\title{
Numerical study of the effect of geometric arrangement of the truss on the response modification factor of the special truss moment frame (STMF)
}

\author{
M. Sadeghpour ${ }^{1} \cdot$ V. R. Kalatjari ${ }^{1} \cdot$ H. Pahlavan ${ }^{1}$
}

Received: 13 January 2021 / Accepted: 10 April 2021

Published online: 26 April 2021

(c) The Author(s) 2021 OPEN

\begin{abstract}
The purpose of the present study was to investigate the effect of the geometric arrangement of the trusses on the response modification factor of the special truss moment frame. For this purpose, six different geometric arrangements for the three types of trusses (Vierendeel, multiple Vierendeel panels, and X-diagonals) were considered. The results were obtained based on non-linear static analysis of two- and three-span frames for 4- and 8-story structures with the given geometric arrangements. According to the results obtained, different truss arrangements can affect the response modification factor by about 4 to $10 \%$. Additionally, using multiple Vierendeel panels and the X-diagonals can increase the response modification factor by 1.06 and 1.74 times, respectively.
\end{abstract}

\section{Article Highlights}

1. Different truss arrangements do not have a significant effect on the coefficient of behavior.
2. The addition of several Vierendeel panels does not have much effect on the behavior of these structures.

3. Adding cross diameters almost doubles the coefficient of behavior and significantly improves the performance of the structure.

Keywords Geometric arrangement $\cdot$ Response modification factor $\cdot$ Special truss moment frame $\cdot$ X-diagonals .

Vierendeel $\cdot$ Multiple vierendeel panels

\section{Introduction}

Considering the damages and injuries caused by earthquakes in high-risk earthquake zones, the need to design earthquake-resistant structures seems undeniable. To design an earthquake-proof building, it is necessary to have comprehensive knowledge about its response against the forces caused by the earthquake. It should be noted that compliance with the code-specified rules and regulations does not guarantee the full resistance of buildings to earthquake forces [1, 2]. Therefore, the response of structures should be considered carefully. This requires an exact explanation of the concepts related to the seismology of strong-motion records and the engineering design criteria [3].

The seismic design philosophy of most building codes around the world allows the structures to undergo inelastic deformations in the event of strong earthquake ground motions. Thus, due to the energy dissipation capacity, the designed lateral strength can be lower than that required

M. Sadeghpour, M.sadeghpour489@gmail.com | 'Faculty of Civil Engineering, Shahrood University of Technology, Shahrood, Iran. 
to maintain the structure in the elastic range during an earthquake [4]. In fact, nonlinear analysis is needed to take advantage of the capacity for the inelastic response when designing the structures. As such analyses are timeconsuming and bulky, most seismic design codes use a force reduction factor (also termed as force reduction factor) to estimate the real response of the structure through relevant elastic analyses. This factor includes conceptualcomputational complexities and depends on various other factors. In general, the same response modification factor cannot be considered for one type of structure and all of its periodic constraints $[5,6]$. Various factors such as earthquake record, frequency content, soil conditions, the type of structural system, the degree of material ductility, the geometric shape of the structure, and the regularity and irregularity of the structure affect the response modification factor $[7,8]$.

The growing population and development of cities and the lack of residential and office spaces in metropolitan areas have led inevitably to the vertical development of cities. Due to urban constraints and the type of used structures in commercial and industrial buildings, the design conditions require that the distance between the columns be greater than the normal one. Therefore, using a suitable and efficient structural system seems necessary from both technical and economic points of view. In these cases, there are various options for designing the building's loadbearing system. One of the most effective and widely-used options is the use of a frame with special truss beams. Such a system can be used with different truss arrangements. Since the previous studies have not investigated the difference in the response modification factor in these truss arrangements, the effect of the geometric arrangement of the truss on the response modification factor of the special truss moment frame has been investigated using various models in the present study. For this purpose, several frame samples were analyzed by changing various parameters such as the number of openings and the number of floors, and finally the overall behavior coefficient of these structures was evaluated.

\section{The special truss moment frame (STMF)}

In recent decades, the use of special truss moment frames has been developed as a relatively new type of steel framing system for earthquake-prone areas [9]. In this type of framing, earthquake energy is dissipated through special ductile segments located near the mid-span of the truss girders, while other segments are designed in such a way that they remain elastic $[10,11]$. These special segments can be built in the form of X-diagonals, Vierendeel, and multiple Vierendeel panels (Fig. 1).

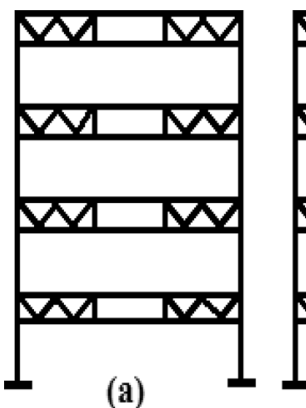

(a)

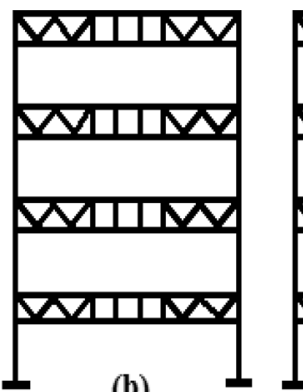

(b)

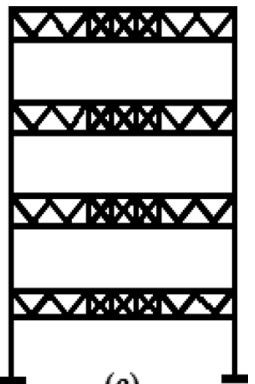

(c)
Fig. 1 The frame with special truss beams

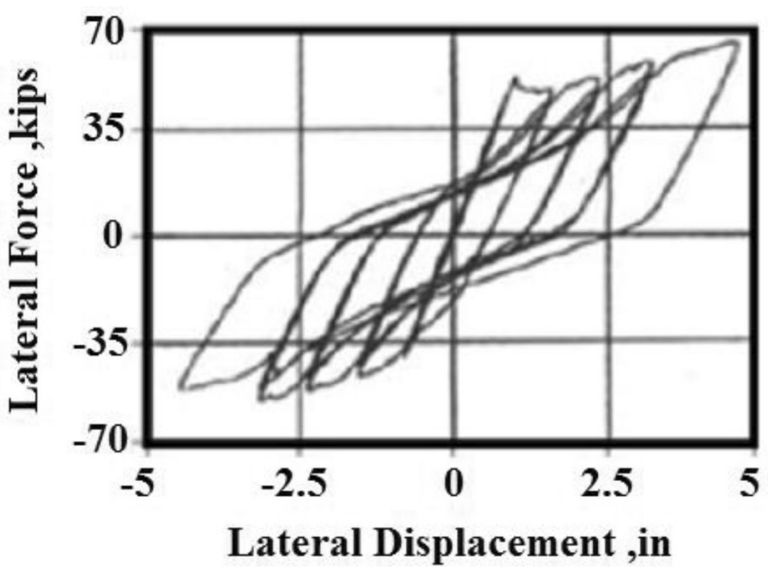

Fig. 2 Hysteresis curve of the special truss frame [16]

The moment frames with special truss beams increase the ductility of the structure by creating a special zone in the middle of the truss beam, and the zone is created by plastic deformation and energy absorption in the middle of the beam [12]. The shear force resulting from the vertical load is small in this zone and this segment can be susceptible to non-elastic deformation and the absorption of earthquake energy if the weaker diagonal members are placed or they are removed [13].

Such systems include an appropriate collapse mechanism against earthquakes. This controlled yield mechanism and inelastic behavior limit the forces of all elements outside the special segment to the ultimate capacity of the special segment. Thus, the system remains elastic[14, 15]. On the other hand, in this type of structural system, it is possible to increase the web members in special segments, the degree of indeterminacy, and the stiffness of the structure. In addition to including an appropriate collapse mechanism for seismic areas, special trusses cause less amount of steel to be consumed [16]. Figure 2 shows the expected hysteresis cycle of special trusses that exhibit much smoother behavior due to the formation of middle plastic members. It is a ductile behavior along with a stable 
hysteretic behavior up to $3 \%$ relative displacement for a large number of cycles.

\section{Response modification factor}

So far, various equations have been proposed to determine the response modification factor of a single-degreeof-freedom system, based on which the response modification factor of the system can be calculated by having its ductility capacity. The response modification factor of multi-degree-of-freedom systems can be calculated by Eq. (1) that consists of the following three parts:

$R=R_{\mu} R_{s} Y$

The first part of it is similar to that of the single-degreeof-freedom systems and is usually represented by $R_{\mu}$. The second part is concerned with the effect of factors specific to multi-degree-of-freedom systems and is represented by $R_{s}$. This factor, called the overstrength factor, has an important role in preventing the collapse of short-period structures against the forces caused by earthquakes. In such structures, ductility does not have much effect on seismic forces. The third part is related to the allowable stress factor $(\mathrm{Y})$, which is applied to the design force to reduce the base shear when the first plastic hinge is formed in the structure [5]. By nonlinear static analysis of a structure, the overall response diagram of it can be obtained. This diagram shows the amount of displacement of the highest level of the structure versus the gradual increase of the base shear forces. Figure 3 shows an example of the curve of the overall response of the structure, provided by the analysis of the increasing nonlinear forces [17].

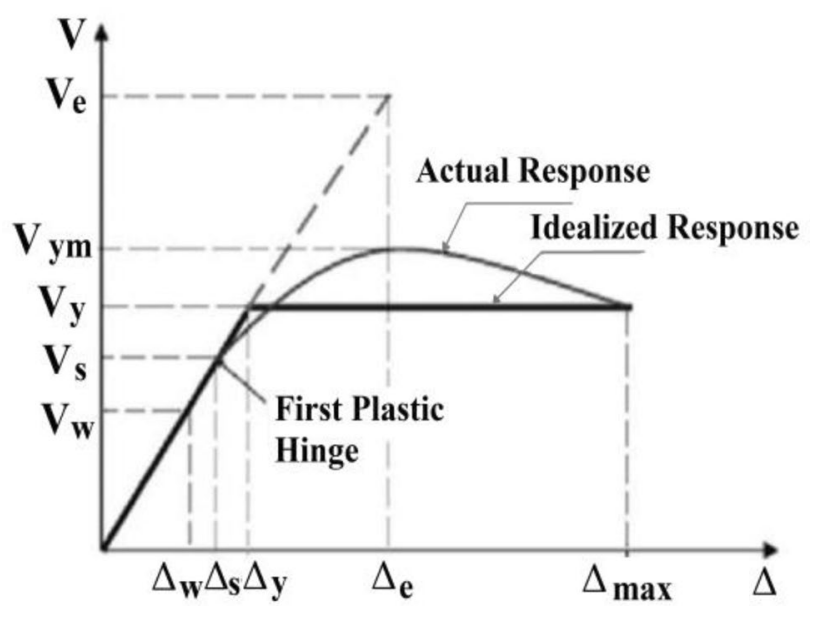

As can be seen in the figure, the real nonlinear response of a structure can be modeled by a double-linear relationship. In this double-linear model, the yield strength level of the structure is represented by $V_{y}$ and the yield displacement is represented by $\Delta_{\mathrm{y}}$. If the linear response of the structure during the earthquake is assumed, the maximum base shear will be equal to $V_{e}$. It is reduced to $V_{y}$ due to the nonlinear behavior of the structure. The maximum displacement of the structure before the collapse of the structure is equal to $\Delta_{\max }$. According to Fig. 3 , the ductility coefficient $\mu$ can be obtained from Eq. (2) [17]:

$\mu=\frac{\Delta_{\max }}{\Delta_{y}}$

Due to the ductility and nonlinear response of the structure, the linear force $V_{e}$ of the structure can be reduced to the force $V y$. Therefore, the force reduction factor can be defined according to Eq. (3):

$R_{\mu}=\frac{V_{e}}{V_{y}}$

It is obvious that the area below the straight line of the linear displacement of the structure, the value of which at the end determines $V_{e^{\prime}}$ is equal to the total energy of the structure. It should be noted that $V_{y}$ corresponds to the structural collapse level, not the level of first significant yielding. In practice, due to the complexity of calculating the $V_{e}$ by the energy method, this parameter is calculated using various equations proposed by various researchers according to the period of the studied structure. In this case, $5 \%$ viscous damping is used in linear response to calculate the period of the studied structure [17].

In this study, the equation proposed by Newmark and Hall (1982) was used to calculate the force reduction factor [18]:

$R_{\mu}=1 \quad T \leq 0.03 \mathrm{sec}$

$R_{\mu}=\sqrt{2 \mu-1} 0.12 \leq T \leq 0.5 \mathrm{sec}$

$R_{\mu}=\mu \quad T \geq 1 \mathrm{sec}$

The reserve strength from the first yield level $V_{s}$ to the final yield level and the formation of the actual collapse mechanism $V_{y}$ is called overstrength. The ratio of these two yield levels is the overstrength factor that is represented by $R_{s}$ and is defined according to Eq. (5):

$R_{s}=\frac{V_{y}}{V_{s}}$

Fig. 3 General behavior of force-displacement of structures 
Structural overstrength results from internal force redistribution, higher material strength than those specified in the design, member yielding, and the formation of various plastic hinges until the structure becomes a mechanism, member oversize, and so on [5].

To design at allowable stress level, the design codes reduce the force $V_{s}$ to the design force $V_{w}$. This reduction is done by the allowable stress factor, which is defined according to Eq. (6):

$Y=\frac{V_{s}}{V_{w}}$

To design steel and reinforced concrete structures by allowable stress method, the range of $1.4-1.5$ is usually considered. This factor for designing by strength design method is equal to 1 .

\section{Numerical modelling and analysis}

To evaluate the effect of truss geometric arrangement on response modification factor of special truss moment frames, 4 and 8-story models with two and three spans and six different geometric arrangements consisting of $x$-diagonals, Vierendeel, and multiple Vierendeel panels have been designed in a two-dimensional form (Fig. 4). In this article, truss arrangements are considered based on all the permitted conditions of the regulations that are normative from the executive point of view. It has been assumed in the designs that the frames are placed in regular plans, as Fig. 5 demonstrates. The process of designing frames has been done based on the AISC Seismic
Provisions (AISC 341-16) [16]. The sections of the designed profiles of the study models are shown in the Table 1 and Fig. 6 . The soil of the construction site has been assumed based on the Iranian Standard Code No. 2800 to be of type 2 and the project area has been considered to be very risky in terms of zoning.

The dead and live loads applied to the structure according to the Iranian National Building Code (Division 6- loading) have been equal to $500 \mathrm{~kg} / \mathrm{cm}^{2}$ and 200 $\mathrm{kg} / \mathrm{cm}^{2}$ for all stories and $500 \mathrm{~kg} / \mathrm{cm}^{2}$ and $150 \mathrm{~kg} / \mathrm{cm}^{2}$ for the roof, respectively [19]. The steel used has been st37 with Young's modulus $E=2 \times 10^{6} \mathrm{~kg} / \mathrm{cm}^{2}$ and the nominal yield strength of $F y=2400 \mathrm{~kg} / \mathrm{cm}^{2}$ and the final strength of $F u=3700 \mathrm{~kg} / \mathrm{cm}^{2}$.

Using OpenSees[20] software, the nonlinear static analysis has been used to extract the parameters affecting the determination of the response modification factor. The type of analysis used has been the displacement control, in which the roof displacement has been considered as the control point. Generally, in nonlinear analyses, the effects of geometric and material nonlinearities are considered. In the present study, the nonlinear geometric effects have been considered as the P-Delta effect and the nonlinear material effects through fiber sections. The response curve has been defined for all members using the Uniaxial Material Steel 01 Command, which is used for steel with the double-linear response and kinematic hardening. The response curve of these materials has been shown in Fig. 7. As can be seen, the response is quite symmetric in the tensile and compressive branches. The hysteretic response curve for the material has been presented in Fig. 8. In this case, the hysteresis rings remain almost constant in the area.
Fig. 4 Geometric arrangements of the studied trusses

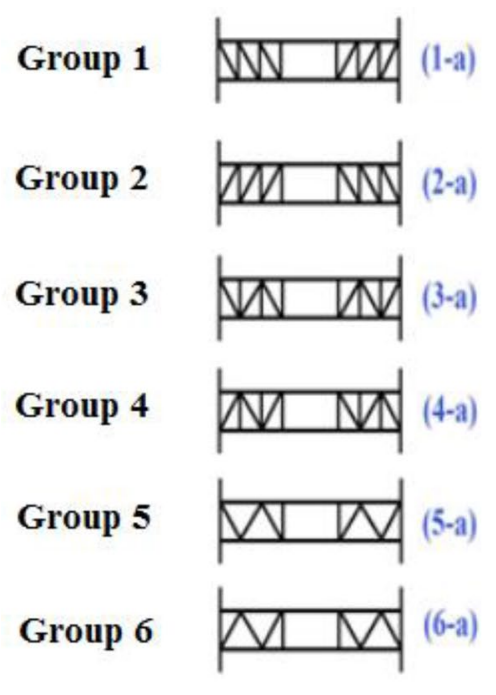

Model (a)
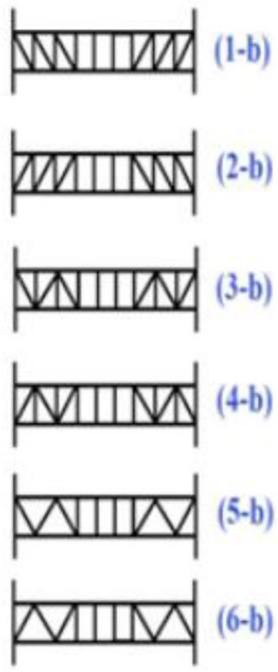

Model (b)
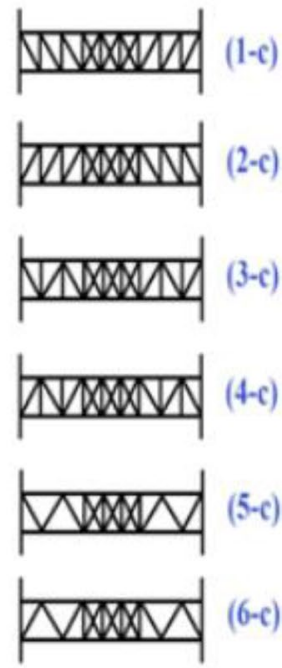

Model (c) 
Fig. 5 Plan and view of the studied models
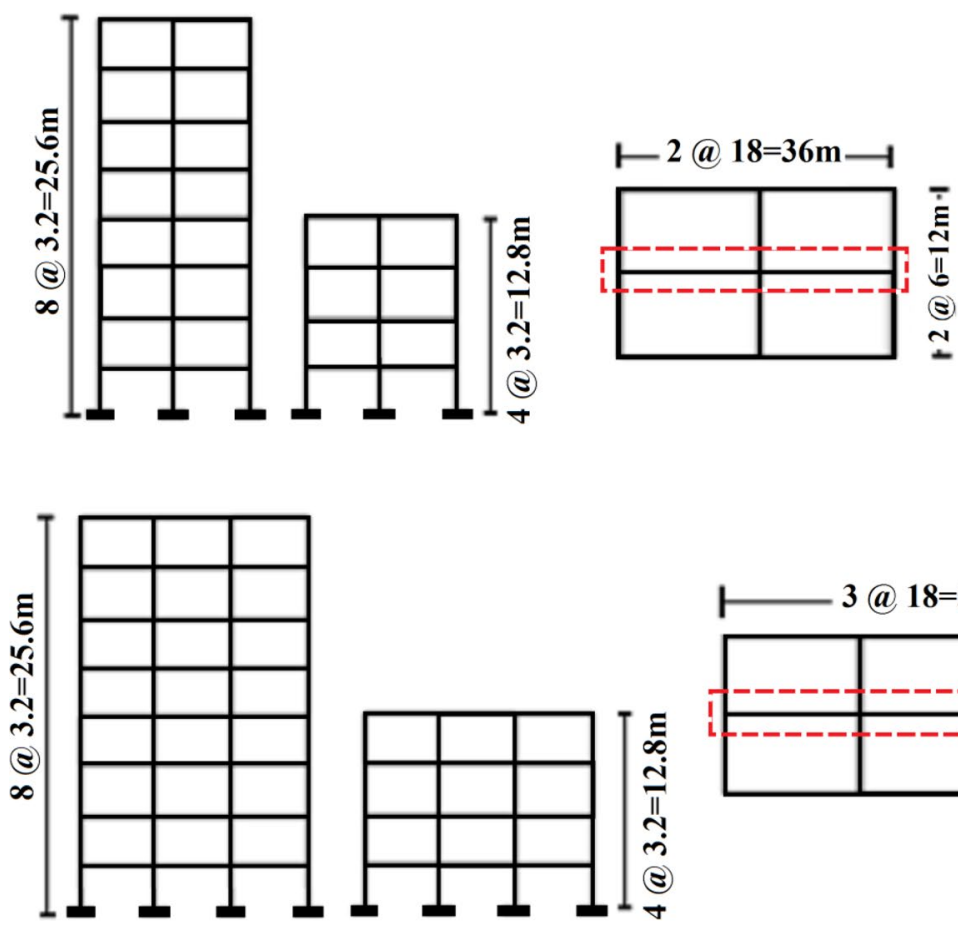

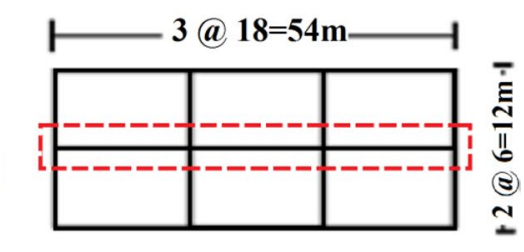

Table 1 The design results of the models

\begin{tabular}{|c|c|c|c|c|c|c|c|c|c|c|c|c|}
\hline Story & Type 1 & Type 2 & Type 3 & Type 4 & Type 5 & Type 6 & Type 7 & Type 8 & $\mathrm{~h}$ & Lp1 & Lp2 & Lp3 \\
\hline & & & 4 & Story & $\_2$ & Span & & & & & & \\
\hline 1_2 & Box $180 * 20$ & UNP80+PL6_2 & UNP80 & UNP80 & UNP80 & UNP80 & UNP80 & UNP80 & 0.9 & 2.25 & 8.55 & _- \\
\hline \multirow[t]{2}{*}{ 3_4 } & Box $180 * 20$ & UNP80+PL5_2 & UNP80 & UNP80 & UNP80 & UNP80 & UNP80 & UNP80 & & & & \\
\hline & & & 4 & Story & _3 & Span & & & & & & \\
\hline 1_2 & $\mathrm{BOX} 350 * 30$ & UNP80+PL20_2 & UNP80 & UNP80 & UNP80 & UNP80 & UNP80 & UNP80 & 0.8 & 3.6 & 8.55 & 8.1 \\
\hline \multirow[t]{2}{*}{ 3_4 } & BOX $350 * 20+2$ PL 20 & UNP80+PL20_2 & UNP80 & UNP80 & UNP80 & UNP80 & UNP80 & UNP80 & & & & \\
\hline & & & 8 & Story & 2 & Span & & & & & & \\
\hline 1_2 & BOX $240 * 20+2$ PL 20 & UNP80+PL6_2 & UNP80 & UNP80 & UNP80 & UNP80 & UNP80 & UNP80 & 1.1 & 3.15 & 4.05 & - \\
\hline 3_4 & BOX $240 * 20+2$ PL20 & UNP80+PL6_2 & UNP80 & UNP80 & UNP80 & UNP80 & UNP80 & UNP80 & & & & \\
\hline $5 \_6$ & BOX240*20+PL20 & UNP80+PL5_2 & UNP80 & UNP80 & UNP80 & UNP80 & UNP80 & UNP80 & & & & \\
\hline \multirow[t]{2}{*}{ 7_8 } & BOX $240 * 20+P L 20$ & UNP80+PL4_2 & UNP80 & UNP80 & UNP80 & UNP80 & UNP80 & UNP80 & & & & \\
\hline & & & 8 & Story & -3 & Span & & & & & & \\
\hline 1_2 & BOX $240 * 30+P L 20$ & UNP80 +PL6_2 & UNP120 & UNP120 & UNP80 & UNP120 & UNP80 & UNP80 & 1.5 & 5.4 & 5.4 & 5.4 \\
\hline 3_4 & $\mathrm{BOX} 240 * 30+\mathrm{PL} 20$ & UNP80 + PL6_2 & UNP120 & UNP120 & UNP80 & UNP120 & UNP80 & UNP80 & & & & \\
\hline 5_6 & $\mathrm{BOX} 240 * 30+\mathrm{PL} 20$ & UNP80 + PL6_2 & UNP120 & UNP120 & UNP80 & UNP120 & UNP80 & UNP80 & & & & \\
\hline 7_8 & BOX $240 * 30$ & UNP80+PL6_2 & UNP120 & UNP120 & UNP80 & UNP120 & UNP80 & UNP80 & & & & \\
\hline
\end{tabular}

\section{Verification}

To ensure the accuracy of the modeling method and the results of nonlinear static analyses, a three-story frame with two spans has been modeled using Sap2000[21] and OpenSees software and the results obtained have been compared. Pushover analysis is carried out by progressively increasing the lateral forces in the inverted triangular shape in order to obtain the roof displacement to $0.02 \mathrm{H}$, where, $\mathrm{H}$ is story height. The results of the vibration modes, obtained from the modal analysis using the two software, can be seen in Table 2. As can be seen in Fig. 9, there has been an acceptable consistency between the results of the nonlinear static analysis using the two software. In the linear region, the response of the two software is compatible due to the elastic behavior. However, in the nonlinear region, we see a $10 \%$ 


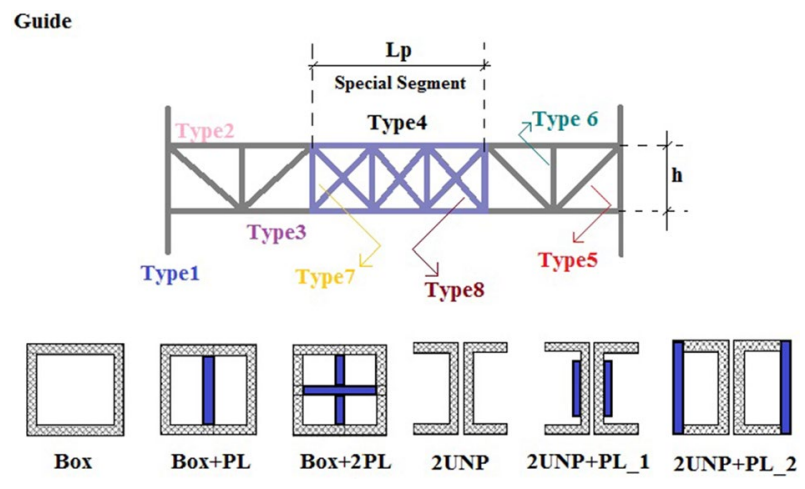

Fig. 6 cross sections

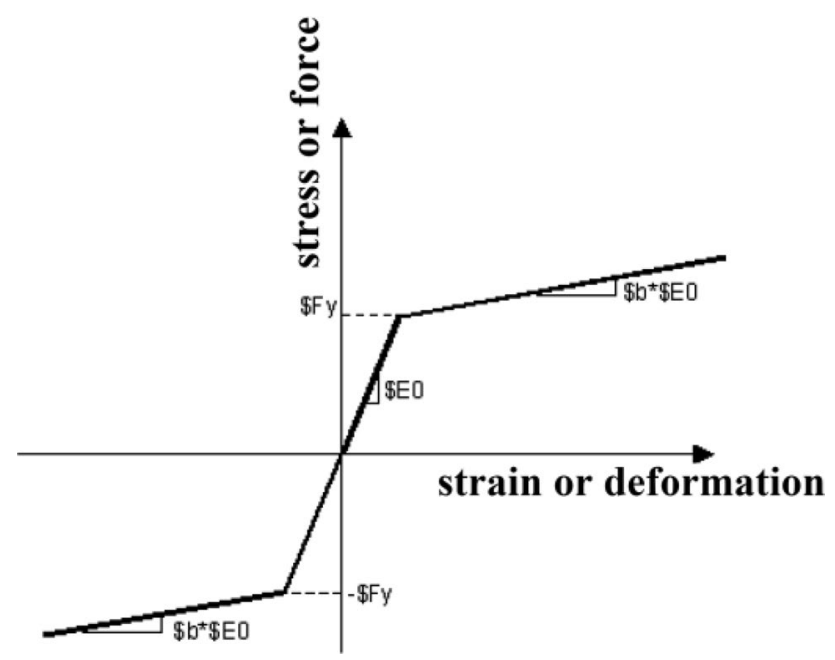

Fig. 7 Response curve for the steel

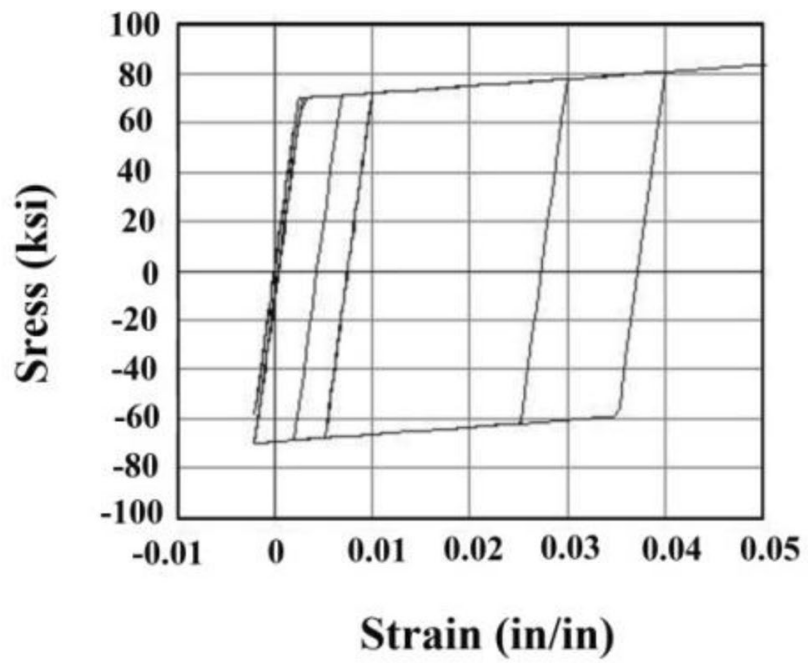

Fig. 8 The model of the cyclic response of Steel 01 without isotropic hardening

SN Applied Sciences
Table 2 Comparison of the period of the first three vibration modes in Sap2000 and OpenSEES

\begin{tabular}{lll}
\hline & OpenSEES & Sap 2000 \\
\hline Mode 1 & $0.8769 \mathrm{~s}$ & 0.87572 \\
Mode 2 & $0.2591 \mathrm{~s}$ & 0.3216 \\
Mode 3 & $0.2192 \mathrm{~s}$ & 0.25033 \\
\hline
\end{tabular}

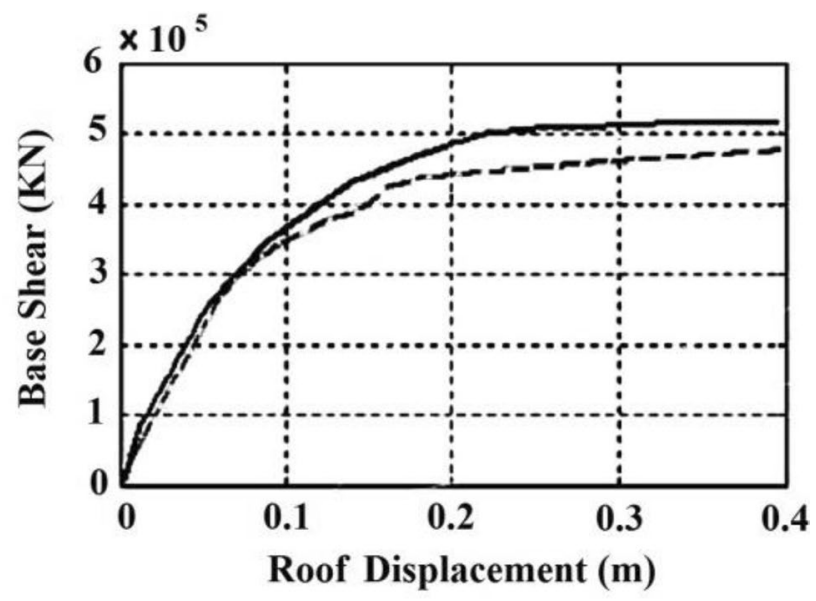

Sap 2000

\section{$== \pm$ OpenSees}

Fig. 9 Verification of results obtained by Sap2000 and OpenSEES

difference between the roof displacements, which is the difference between the nonlinear results of Sap2000 and OpenSEES due to the difference in How to model nonlinearly these two softwares. In nonlinear analysis, Sap2000 software considers the components as concentrated plasticity with the plastic joint, and finally, the formation of plastic joints in it is the point. However, In OpenSEES software, the non-linearity of the elements is done by the fiber element, which works based on extensive plasticity and more accurate than the concentrated plastic joint model. Finally, it leads to the formation of plastic joints regionally and more accurate results.

\section{Results of non-linear static analysis}

As noted, nonlinear static analysis has been used to obtain parameters affecting the determination of the response modification factor. Figure 10 shows the results of the analyses performed using OpenSEES for different geometric arrangements of the 4-story 2-span frame. As shown in Fig. 10, the maximum base shear for model $C$ ( $x$-diagonals) has had the highest value. According to the figure, it can be seen clearly that the qualitative trend of change in base shear has almost been the same for models $A$ and $B$ and only their quantitative values are different. The response 
Fig. 10 Pushover curves of different geometric arrangements of the 4-story 2-span structure
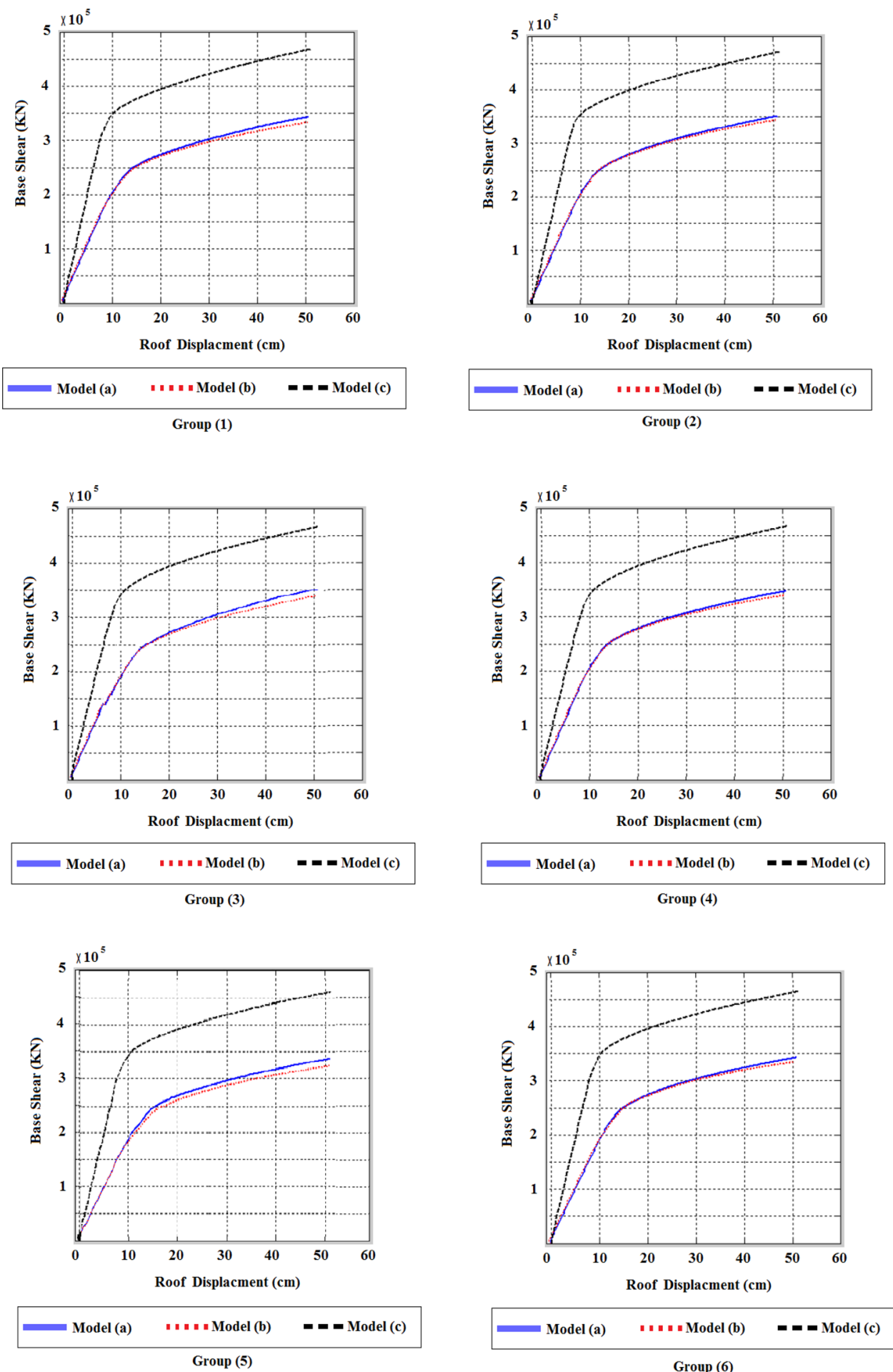

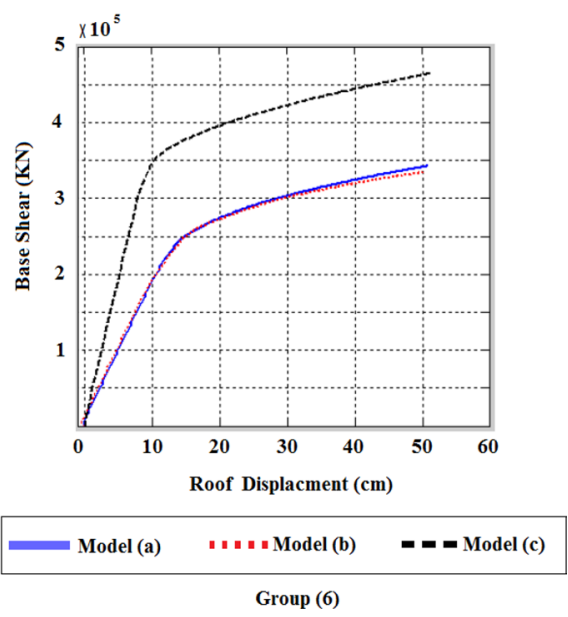

modification factors have been calculated based on the pushover curves. The computational values of the behavior coefficient have been presented in Table 3 .

Figures 11 and 12 show the ductility coefficient of two- and three-span frames. The results show that with increasing the number of openings, the ductility coefficient decreases. In addition, the comparison of curves for 4- and 8-story frames shows that in 4-story frames this amount of reduction is more noticeable.

Figures 13 and 14 also show the ductility coefficient of 4 and 8 floor frames. According to the shapes, with increasing the height of the structure, the ductility coefficient for the 3-span frame has increased. But for a 2-span frame in different truss arrangements, there is no fixed trend. 
Table 3 Results from pushover analysis

\begin{tabular}{lllllllll}
\hline Model & $\begin{array}{l}4 \text { Story } \\
\text { Rs }\end{array}$ & $\begin{array}{l}-2 \text { Span } \\
\mathrm{R} \mu\end{array}$ & $\begin{array}{l}4 \text { Story } \\
\mathrm{Rs}\end{array}$ & $\begin{array}{l}-3 \text { Span } \\
\mathrm{R} \mu\end{array}$ & $\begin{array}{l}8 \text { Story } \\
\mathrm{Rs}\end{array}$ & $\begin{array}{l}-2 \text { Span } \\
\mathrm{R} \mu\end{array}$ & $\begin{array}{l}8 \text { Story } \\
\mathrm{Rs}\end{array}$ & $\begin{array}{l}-3 \text { Span } \\
\mathrm{R} \mu\end{array}$ \\
\hline 1-a & 1.7 & 4.11 & 1.64 & 3.01 & 1.63 & 4.07 & 1.76 & 3.41 \\
2-a & 1.66 & 4.19 & 1.6 & 2.9 & 1.62 & 4.08 & 1.75 & 3.42 \\
3-a & 1.75 & 3.89 & 1.65 & 3.07 & 1.6 & 4.12 & 1.73 & 3.46 \\
4-a & 1.75 & 3.97 & 1.65 & 2.94 & 1.63 & 4.06 & 1.72 & 3.48 \\
5-a & 1.62 & 3.87 & 1.6 & 3.81 & 1.64 & 3.57 & 1.7 & 3.35 \\
6-a & 1.51 & 4.06 & 1.6 & 2.96 & 1.65 & 3.66 & 1.71 & 3.33 \\
1-b & 1.65 & 4.53 & 1.47 & 3.85 & 1.59 & 4.25 & 1.56 & 4.3 \\
2-b & 1.66 & 4.27 & 1.46 & 3.72 & 1.55 & 4.44 & 1.54 & 4.35 \\
3-b & 1.59 & 4.68 & 1.45 & 3.89 & 1.56 & 4.33 & 1.55 & 4.33 \\
4-b & 1.7 & 4.45 & 1.45 & 3.88 & 1.53 & 4.5 & 1.6 & 3.88 \\
5-b & 1.54 & 4.22 & 1.48 & 3.44 & 1.56 & 3.87 & 1.59 & 3.88 \\
6-b & 1.46 & 4.48 & 1.47 & 3.48 & 1.55 & 4.03 & 1.5 & 4.14 \\
1-c & 1.53 & 6.67 & 2.01 & 4.47 & 1.93 & 7.15 & 1.95 & 6.71 \\
2-c & 1.49 & 7.15 & 1.99 & 4.29 & 1.99 & 6.85 & 1.86 & 5.5 \\
3-c & 1.53 & 6.3 & 2.01 & 4.53 & 1.96 & 7.03 & 1.94 & 6.74 \\
4-c & 1.48 & 6.52 & 1.98 & 3.45 & 2.02 & 6.86 & 1.69 & 4.65 \\
5-c & 1.53 & 6.29 & 1.97 & 4.38 & 1.94 & 6.52 & 1.98 & 5.23 \\
6-c & 1.43 & 6.72 & 1.94 & 4.24 & 1.89 & 6.73 & 1.71 & 3.98 \\
\hline
\end{tabular}

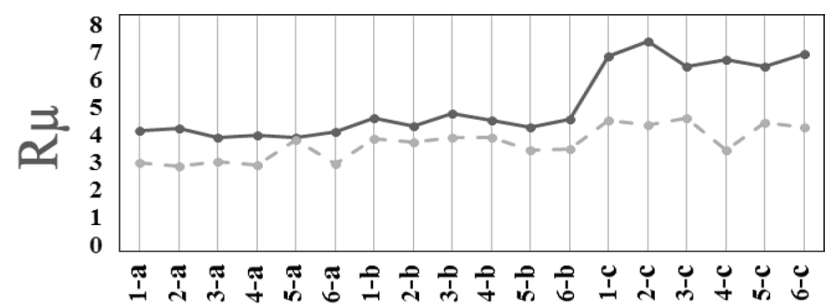

Model

$\rightarrow 4$ Story - 2 Span $\quad-\leftarrow 4$ Story - 3 Span

Fig. 11 The ductility coefficient of 4-story 2-span and 3-span structure

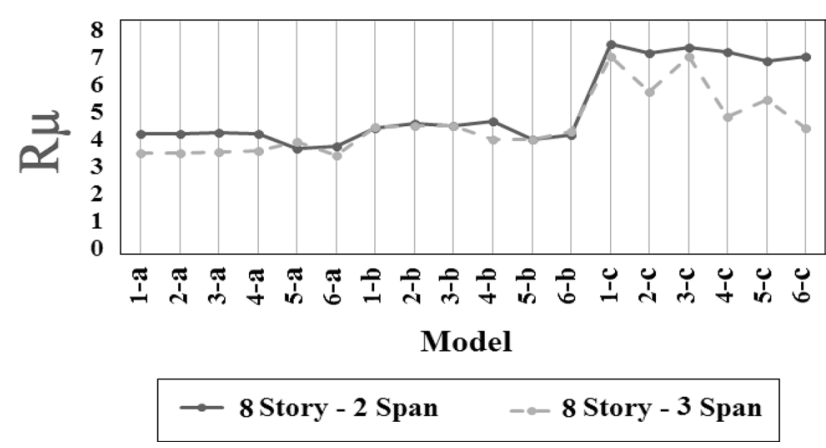

Fig. 12 The ductility coefficient of 8-story 2-span and 3-span structure

\section{SN Applied Sciences}

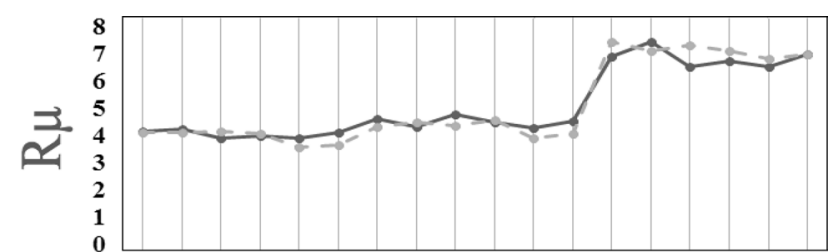

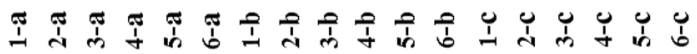

\section{Model}

$\rightarrow 4$ Story - 2 Span $\quad-6$ Story - 2 Span

Fig. 13 The ductility coefficient of 4- and 8-story 2-span structure

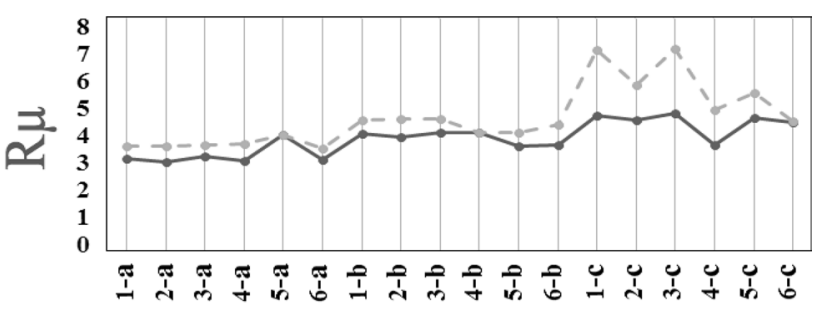

Model

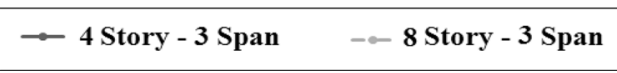

Fig. 14 The ductility coefficient of 4- and 8-story 2-span structure 
Table 4 The response modification factors of 4-story 2-span structure

\begin{tabular}{lllllll}
\hline & Model (a) & R & Model (b) & R & Model (c) & R \\
\hline Group 1 & 1_a & 6.9878 & 1_b & 7.4754 & 1_c & 10.2 \\
Group 2 & 2_a & 6.9638 & 2_b & 7.0914 & 2_c & 10.658 \\
Group 3 & 3_a & 6.8174 & 3_b & 7.4557 & 3_c & 9.6377 \\
Group 4 & 4_a & 6.9573 & 4_b & 7.56 & 4_c & 9.658 \\
Group 5 & 5_a & 6.2744 & 5_b & 6.5057 & 5_c & 9.6364 \\
Group 6 & 6_a & 6.1406 & 6_b & 6.5457 & 6_c & 9.6204 \\
\hline
\end{tabular}

Table 5 The response modification factors of 4-story 3-span structure
Table 6 The response modification factors of 8-story 2-span structure

\begin{tabular}{lllllll}
\hline & Model (a) & R & Model (b) & R & Model (c) & R \\
\hline Group 1 & 1_a & 4.9429 & 1_b & 5.6606 & 1_c & 8.99 \\
Group 2 & 2_a & 4.6441 & 2_b & 5.4321 & 2_c & 8.5544 \\
Group 3 & 3_a & 5.0717 & 3_b & 5.6451 & 3_c & 9.1178 \\
Group 4 & 4_a & 4.8605 & 4_b & 5.6289 & 4_c & 6.8457 \\
Group 5 & 5_a & 6.1073 & 5_b & 5.097 & 5_c & 8.6473 \\
Group 6 & 6_a & 4.7464 & 6_b & 5.1214 & 6_c & 8.2253 \\
\hline
\end{tabular}

\begin{tabular}{lllllll}
\hline & Model (a) & R & Model (b) & R & Model (c) & R \\
\hline Group 1 & 1_a & 6.6394 & 1_b & 6.7715 & 1_c & 13.8082 \\
Group 2 & 2_a & 6.6202 & 2_b & 6.8881 & 2_c & 13.6466 \\
Group 3 & 3_a & 6.60747 & 3_b & 6.76547 & 3_c & 13.7829 \\
Group 4 & 4_a & 6.6222 & 4_b & 6.8905 & 4_c & 13.8622 \\
Group 5 & 5_a & 5.8652 & 5_b & 6.0489 & 5_c & 12.7466 \\
Group 6 & 6_a & 6.039 & 6_b & 6.2608 & 6_c & 12.738 \\
\hline
\end{tabular}

Table 7 The response modification factors of 8-story 3-span structure

\begin{tabular}{llllllc}
\hline & Model (a) & R & Model (b) & R & Model (c) & R \\
\hline Group 1 & 1_a & 6.0084 & 1_b & 6.7193 & 1_c & 13.0983 \\
Group 2 & 2_a & 5.9989 & 2_b & 6.707 & 2_c & 10.2403 \\
Group 3 & 3_a & 5.9966 & 3_b & 6.7164 & 3_c & 13.0776 \\
Group 4 & 4_a & 5.9982 & 4_b & 6.2217 & 4_c & 7.86016 \\
Group 5 & 5_a & 5.7033 & 5_b & 6.1799 & 5_c & 10.3687 \\
Group 6 & 6_a & 5.7016 & 6_b & 6.222 & 6_c & 6.8206 \\
\hline
\end{tabular}

The computational behavior coefficient of the models can be seen in Tables 4, 5, 6, and 7. In Figs. 15, 16, 17, and 18 , the diagrams of response modification factors of the models have been presented. As can be seen, based on the results obtained from these diagrams, the response modification factors are almost equal in models 1 to 4 of series $\mathrm{A}$ (Vierendeel), but there is a $9 \%$ decrease in the response modification factors in models 5 and 6 compared to the other 4 models of this series. The same trend can also be seen in the models of series B (multiple Vierendeel panels). It is worth noting that no certain trend can be seen in the models of the series $C$ (X-diagonals), which is more noticeable with the increase in the number of spans in the models.

Figures 19 and 20 show the ratio of the response modification factors of series B (multiple Vierendeel panels) and series $C$ ( $x$-diagonals) of each group to the response modification factors of series $A$ (Vierendeel) of the same group, respectively. As Fig. 19 shows, compared to the models with a Vierendeel panel, no significant increase (3-9\%) can be seen in the response modification factors of models with multiple Vierendeel panels. The increase in the number of spans in the models has made this increase more noticeable. 


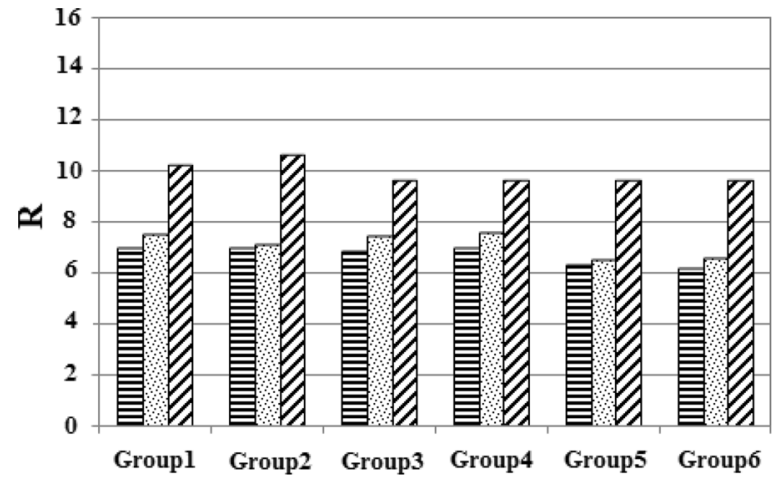

目 Model (a) 图 Model (b) $\square$ Model (c)

Fig. 15 Comparison of the response modification factors of the studied models of the 4-story 2-span structure

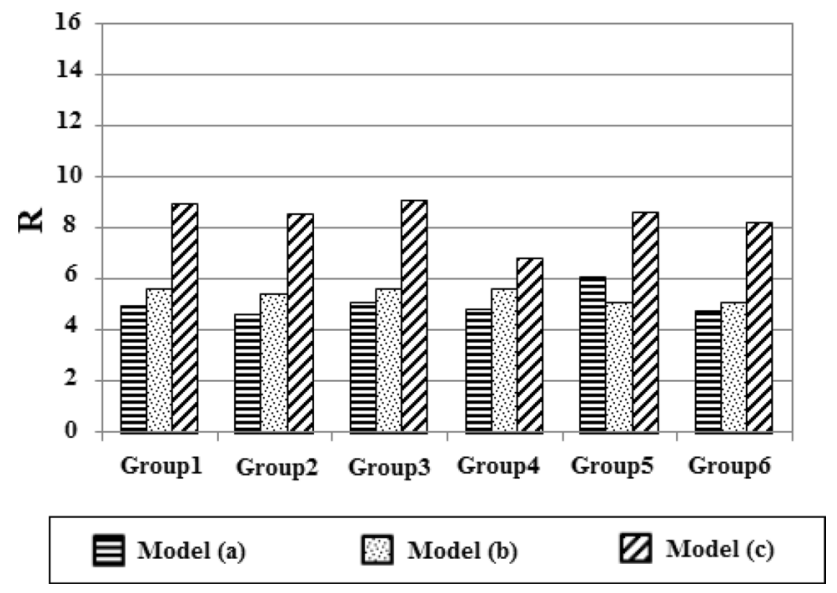

Fig. 16 Comparison of the response modification factors of the studied models of the 4-story 3-span structure

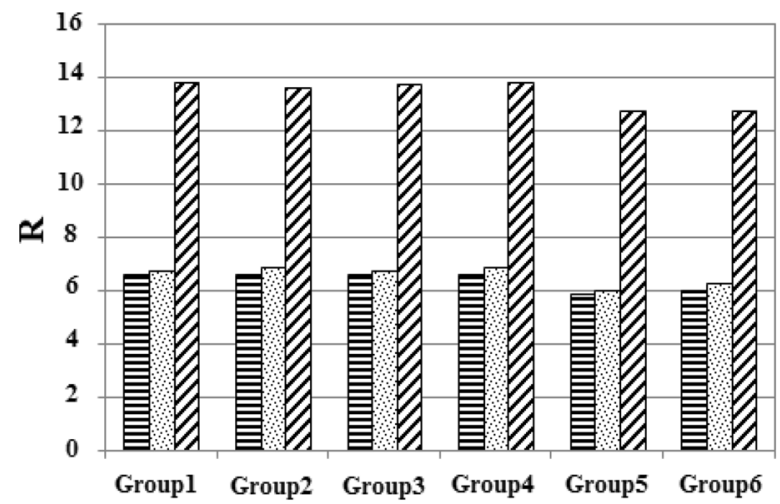

目 Model (a) 国 Model (b) $\square$ Model (c)

Fig. 17 Comparison of the response modification factors of the studied models of the 8-story 2-span structure

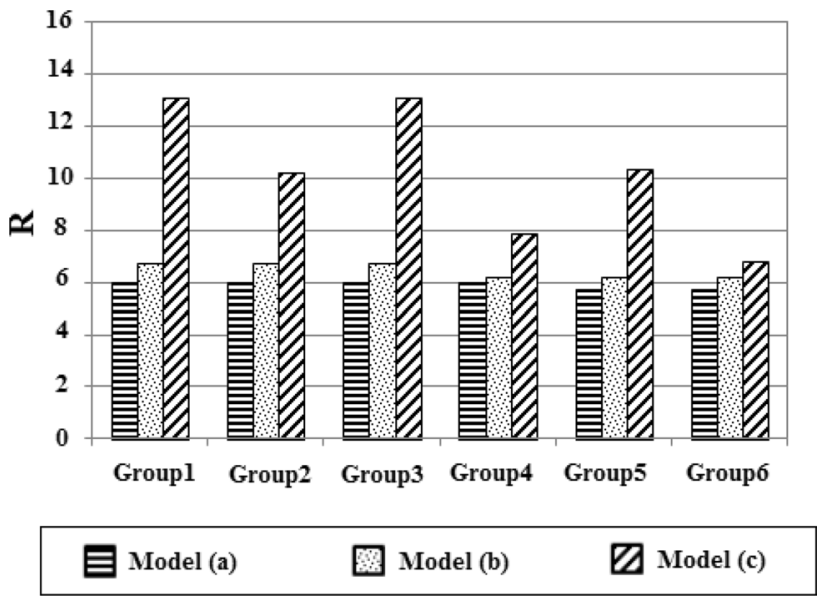

Fig. 18 Comparison of the response modification factors of the studied models of the 8-story 3-span structure

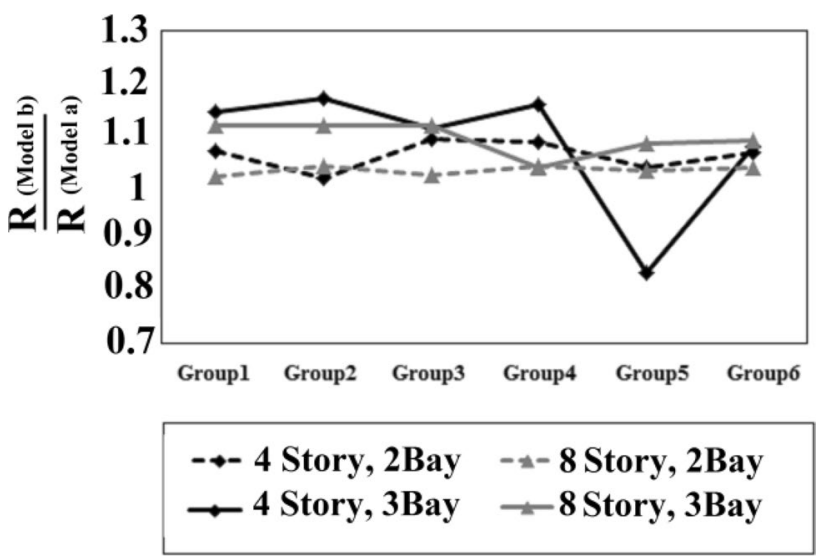

Fig. 19 Computational ratio of the response modification factors of models with multiple Vierendeel panels to those of models with a Vierendeel panel

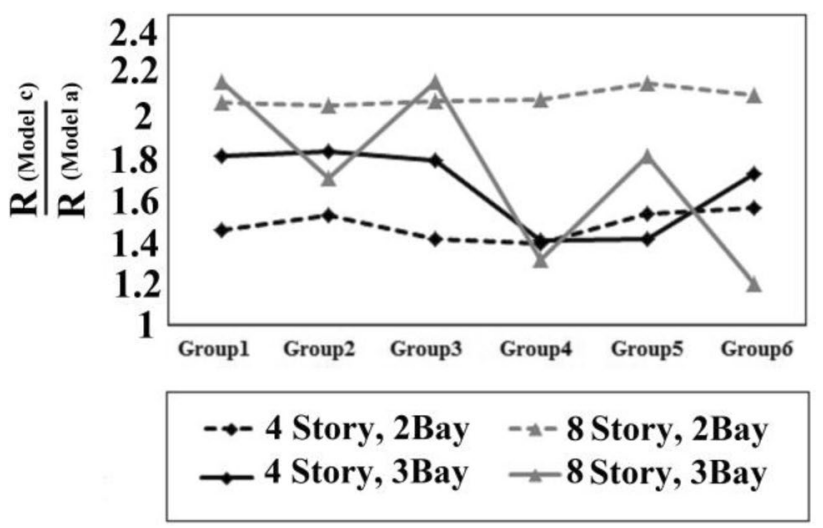

Fig. 20 Computational ratio of the response modification factors of models with $x$-diagonals to those of models with a Vierendeel panel 
However, this increase becomes less as the height increases. According to Fig. 20, the addition of X-diagonals to models with multiple Vierendeel panels has resulted in a significant increase $(48 \%-110 \%)$ in their response modification factors compared to the models with a Vierendeel panel. This increase becomes more as the height increases, and the increase in the number of spans in 4-story models leads to an increase in the response modification factors. However, in the 8-story model, a steady trend cannot be seen, and on average, an increase in the number of spans causes the increase in the response modification factors to be less.

\section{Conclusion}

In the present study, the effect of the geometric arrangement of the truss on the response modification factor of the special truss moment frame was investigated by nonlinear static analysis. Based on the results of the study, it can be explained that the different arrangements of trusses in models with one and multiple Vierendeel panels increase on average the value of response modification factors by about $4 \%$. However, the addition of $x$-diagonals to the models causes the increase to be more and the value of response modification factors increases on average by about $10 \%$. Additionally, the use of multiple Vierendeel panels leads to the relative improvement of seismic performance and the increase in the response modification factors by about $6.8 \%$ compared to the models with a Vierendeel panel. It is worth noting that by adding X-diagonals to models with multiple Vierendeel panels, the response modification factor of the system improves significantly so that it increases on average by $74.6 \%$ compared to the models with a Vierendeel panel. In this article, in order to simplify modeling, a two-dimensional frame has been used. As a further study, the effect of three-dimensional modeling can be investigated.Also the effect of truss height and special segment panel opening dimensions on the coefficient of behavior needs further study.

Acknowledgement The authors wish express their sincere thanks to the anonymous reviewers for their constructive comments that have helped improving the quality of this paper.

\section{Declarations}

Conflict of interest The authors declare that they have no conflict of interest.
Open Access This article is licensed under a Creative Commons Attribution 4.0 International License, which permits use, sharing, adaptation, distribution and reproduction in any medium or format, as long as you give appropriate credit to the original author(s) and the source, provide a link to the Creative Commons licence, and indicate if changes were made. The images or other third party material in this article are included in the article's Creative Commons licence, unless indicated otherwise in a credit line to the material. If material is not included in the article's Creative Commons licence and your intended use is not permitted by statutory regulation or exceeds the permitted use, you will need to obtain permission directly from the copyright holder. To view a copy of this licence, visit http://creativecommons. org/licenses/by/4.0/.

\section{References}

1. Moustafa A, Takewaki I (2010) Deterministic and probabilistic representation of near-field pulse-like ground motion. Soil Dyn Earthq Eng 30:412-422

2. Bray JD, Rodriguez-Marek A (2004) Characterization of forwarddirectivity ground motions in the near-fault region. Soil Dyn Earthq Eng 24:815-828

3. Burks LS, Baker JW (2016) A predictive model for fling-step in nearfault ground motions based on recordings and simulations. Soil Dyn Earthq Eng 80:119-126

4. Mahmoudi M, Zaree M (2010) Evaluating response modification factors of concentrically braced steel frames. J Constr Steel Res 66(10):11961204

5. Massumi A, Tasnimi AA, Saatcioglu M, (2004) August. Prediction of seismic overstrength in concrete moment resisting frames using incremental static and dynamic analyses. In 13th world conference on earthquake engineering (pp. 1-6)

6. Mahmoudi M, Zaree M, (2013) Performance based design using force reduction factor and displacement amplification factors for BFS

7. Reyes-Salazar A, Bojórquez E, Bojórquez J, Valenzuela-Beltran F, Gaxiola-Camacho JR, Haldar A (2019) Seismic reduction factor evaluation and its components for steel buildings undergoing nonlinear deformations. Curr Sci 116(11):1850

8. Patil DM, Sangle KK (2015) August. Seismic behaviour of different bracing systems in high rise 2-D steel buildings. Structures 3:282-305

9. Goel SC, Itani AM (1994) Seismic-resistant special truss-moment frames. J Struct Eng ASCE 120(6):1781-1797

10. Basha H, Goel SC (1994) "Seismic resistant truss moment frames with ductile vierendeel segment". Report No. UMCEE 94-29, Ann Arbor, Department of Civil and Environmental Engineering, University of Michigan

11. Basha HS, Goel SC (1995) Special truss moment frames with vierendeel middle panel. Eng Struct 17(5):352-358

12. Chao SH, Goel SC (2008) Performance-based plastic design of special truss moment frames. Eng J 45(2):127

13. Chao SH, Goel SC (2008) A modified equation for expected maximum shear strength of the special segment for design of special truss moment frames. Eng J 45(2):117-126

14. Yang TY, Yuanjie Li, Leelataviwat L (2014) Performance-based design and optimization of buckling restrained knee braced truss moment frame. J Perform Constr Facil ASCE 28(6):A4014007

15. Abdollahzadeh G, Sazjini M, Asghari A (2015) Seismic fragility assessment of special truss moment frames (STMF) using the capacity spectrum method. Civ Eng Infrastruct J 48(1):1-8

16. AISC (2016) "Seismic provisions for structural steel buildings". ANSI/ AISC 341-16, American Institute of Steel Construction, Chicago, Illinois 
17. Uang C, Establishing R (1991) Cd factors for building seismic provisions, ASCE. J Struct Eng 177:19-28

18. Newmark NM, Hall WJ (1982) Earthquake spectra and design. Earthquake Eng. Research Institute, Berkeley, CA

19. Iranian National Building Code (2014) (Design Loads for Buildings - Division 6), Tehran, Iran

20. OpenSees (2013) Open system for earthquake engineering simulation, version 2.4.5, Pacific Earthquake Engineering Research Center: University of California, Berkeley, from: http:// opensees. berkeley.edu/
21. CSI (2010) Analysis reference manual for sap2000. Berkeley-California, USA

Publisher's Note Springer Nature remains neutral with regard to jurisdictional claims in published maps and institutional affiliations. 